\title{
Quality and safety systems for the port industry: empirical evidence for the main Greek ports
}

\author{
Constantinos I. Chlomoudis • Petros A. Kostagiolas • \\ Christos D. Lampridis
}

Received: 21 March 2010 / Accepted: 7 December 2010 /Published online: 15 June 2011

(C) The Author(s) 2011. This article is published with open access at SpringerLink.com

\begin{abstract}
Purpose Quality is a complex and subjective concept, incorporating at any given time the true (expressed and implied) needs of all those involved. Over the last two decades, safety and security are becoming increasingly important to the extent that they may be considered to be synonymous or entirely integrated to quality. The aim of this paper is twofold a. to investigate contemporary issues for quality and safety/security systems integration within port industry and $b$. to empirically assess the penetration of quality and safety international standards in the major Greek ports.

Methods A review of the literature is conducted and the results of a survey conducted based on semi-structured interviews to the top management of 10 out of the 12 Greek major ports are presented.

Results The qualitative analysis provide evidence for the interrelation and integration of quality and safety/security
\end{abstract}

On behalf of the authors it is stated that, the work submitted has not been published and is not being considered for publication elsewhere.

\section{I. Chlomoudis}

Department of Maritime Studies, University of Piraeus,

40 Karaoli and Dimitriou Str,

18532 Piraeus, Greece

e-mail: chlom@unipi.gr

P. A. Kostagiolas $(\bowtie)$

Department of Archive \& Library Science, Ionian University,

72 Ioannou Theotokis str,

49100 Corfu, Greece

e-mail: pkostagiolas@ionio.gr

C. D. Lampridis

Laboratory of Integrated Port Economy and Management,

University of Piraeus,

40 Karaoli and Dimitriou Str,

18532 Piraeus, Greece

e-mail: clamprid@yen.gr standards; while the survey exhibit the benefits, the motives and the shortcomings of the quality and safety certification in the major Greek ports.

Conclusions Integration of quality and safety management systems in ports has several advantages. The survey indicated that safety and environmental issues are a priority for most major Greek ports; while a growing interest on ISO 9001 certification is evident.

Keywords Port industry. Quality. Safety. Security. Greece · Survey

\section{Introduction}

Quality is a relative concept with a social and a market driven content, relating stakeholder real (implied and expressed) needs to port operations and management actions. The search for demonstrating quality and safety in the maritime transportation services and ports in particular has quite a long history and has become the "Holy Grail" for researchers around the world. Ports as far as quality is concerned are indeed an important part of the maritime transportation chain [1]. Recently researchers (e.g. [2]) investigated compatibility issues among international conventions for safety and environmental management with the well known quality assurance schemes such as ISO 9000. This effort for quality and safety approaches integration, together with the maritime conventions, may have advantages and is expected to increase the competitiveness of ports. Although considerable steps have been made over the last decade, reality is fraught with problems and there is no doubt that over the next period of time quality and safety/security interrelation ought to be further considered. 
Indeed, the discussion on quality and safety issues for ports all over the world has never been as intense as that experienced in recent years [3]. The motive behind this study comprises both a theoretical and a practical aspect: In a theoretical perspective, the motivation of this work refers to the need for an integrated port assurance paradigm which will include quality, safety and security concerns and requirements. Globalization has radically increased competition and changed the quality/safety/security landscape. Over the last two decades a myriad omnibus and/or specific initiatives, standards, and regulations within maritime industry have been introduced at a national, an EU and an international level. In a rather practical perspective, the significant amount of experience accumulated in ports around the world over the years may enlighten the applicability, benefits and drawbacks of current efforts in terms of quality, safety and security implementations. Although some applicable theoretical results have recently been made available in the literature, there is paucity of empirical research on the integration of quality and safety systems in ports. Ports in Europe need to further address such issues due to the competition within a rapidly changing transportation environment which places quality and safety in the centre of all activities.

The objective of this paper is twofold a. to investigate contemporary issues on quality and safety within the port industry and $b$. to empirically assess the perceptions for quality and safety management implementation in major Greek ports. In the following section a brief overview of the distinct approaches for quality and safety management in ports is initially provided. The analysis also provides evidence on the need for quality and safety systems integration in ports. Furthermore, the first theoretical section points out that no approach should be perceived as a panacea and more than one ought to be considered. Thereafter, quality and safety standards implementation in Greek ports is discussed and the results of a survey, which was conducted during the second quarter of 2008 through semi-structured interviews, are presented.

\section{Inferences on integrating quality and safety/security management in the port industry}

A search of the relevant port management literature [4] illustrates that over the last two decades, national and international organisations have developed and introduced various generic approaches that pertain to the implementation of process-oriented management systems, quality, security and safety assurance standards, Total Quality Management programmes and various accreditation models and international legislations and conventions. Prior to proceeding any further, however, it might be useful to provide a brief overview of the main approaches related to quality as have evolved since the middle of the last century (e.g.[5]) from Inspection and Control to Quality Assurance, Quality Management Systems and Total Quality Management. Each of the above mentioned "quality eras" was build upon the previous one. As quality approaches were evolving, the quality concerned a wider part of the organization and higher levels of interaction with the outside environment were established. The different quality approaches are placing emphasis on three distinct quality philosophies a) quality detection (inspection \& control), b) quality prevention (quality assurance) and c) continuous improvement (Total Quality Management). The recent maritime catastrophes and other international events such as shipping and port accidents, terrorism, concerns on the role of the human element in maritime industry, environmental disasters influence the maritime community for increasing the level of persuasions [2]. Moreover, distinctions among ports are important and the possible scenarios for assuring or enhancing quality and safety are certainly quite a few [4]. Nowadays, quality for port services needs to be custom-made and extends beyond matters dealing with port organization, and comprises internal and external safety and security issues related to the services offered.

The ISO 9000 comprises a well known series of standards that may create the basis on which a port can certify a quality management system. More specifically, ISO 9000 is a family of standards that has been initially introduced in 1987. The latest version of this family of standards includes guidelines and important information on various aspects of quality management implementation (e. g. fundamentals and vocabulary, guidelines for quality plans, guidance on statistical techniques, measurement processes and measuring equipment, guidelines for realizing financial and economic benefits, guidelines for quality and/or environmental management systems auditing etc.) and the ISO 9001:2008 "Quality management systemsRequirements", is the only standard that includes the requirements for certification. This latest version is based on the quality management principles, addressed in ISO 9000 and ISO 9004, i.e. customer-focused organization, leadership, process approach, system approach to management, continual improvement, factual approach to decision making, and mutually beneficial supplier relationship. The process approach nature of ISO 9001 implies that the organization to function effectively, has to determine and link activities though a properly developed documentation in order to transform inputs into outputs. This coherent set of standards has a high rate of compatibility with other standards including those for safety and security. A review on the application of the older version of ISO 9001:2000 in shipping operations and its integration with safety management is provided by Celik [2]. 
Quality is a multidimensional concept directly related to specific organizational goals that should be looked upon as a never ending upward spiral. In accordance to ISO 9000:2005 standards quality may be defined as the provision of products and/or services, which meet stakeholder needs (implicit \& explicit) and expectations[6]. Lopez and Poole [7] have indicated that "safety and security" is indeed an important port services quality attribute as follows (modified in the lines of Lopez and Poole, [7]):

Efficiency: Technical aspects and efficiency of the port product and/or services in terms of cost -benefit results for both the user and the port stakeholders.

Timeliness: Time consistency and reliability of the provided products and/or services within acceptable by the user a priori defined time of initiation and completion for the provision of the required port services.

Safety \& Security: Safety and security conditions and terms involved when handling and managing services related to user property as well as safety conditions related to the working conditions and environmental issues.

Contemporary quality approaches within the port industry ought to encompass a. the traditional customer requirements which are focusing on internal factors within ports and $b$. the requirements that are generated by different interested parties advancing the concept of quality to a stakeholder viewpoint focusing on external factors such as safety, security and environmental standards. Nowadays, safety and security are becoming increasingly important to the extent that they may be considered to be synonymous or entirely integrated to "quality".

So far, due to the uniqueness of the port environment, port specific quality management initiatives were established (e.g. [8, 9]). These include the case of the port of Valencia, with the port specific quality management system referred to as MARCA [7] and the Port of Nantes/ Saint Nazaire with its continuous improvement program for port services [10]. In some cases (e.g. passenger port terminals) port service quality can be studied through a user-centred viewpoint, employing both qualitative and quantitative methods. A group of different approaches evolve from the research on service quality [2] and methodologies of this nature further include port choice behaviour and other customer satisfaction surveys (e.g. [11-14]), the SERVQUAL model (e.g. [9-17]). Indeed, the SERVQUAL approach defines service quality as the difference between port users' expectations and perceptions. An alternative approach is to evaluate the quality and safety level through criteria that cover the full range of stakeholder views (e.g. [8-19]). Indeed, quality and safety management is then focused on a number of "carefully" chosen measurements that are aligned with its mission and strategies, and they may provide an indicative picture of quality and safety levels [20]. Due to the diverse situation of ports throughout Europe, an omnibus criteria setting for all ports may be proven to be a potentially controversial exercise [21].

Environmental and other safety issues are well established [22] among ports and are addressed through the implementation of international standards. In the USA the American Association of Port Authorities [25] developed a manual for environmental management in ports. European Sea Ports Organization [3] published an environmental code of practice for EU ports. Furthermore, ESPO carried out empirical research [23] in cooperation with ECOPORTS in 2004, including 129 ports, which was shown that safety and environmental issues are of growing importance to EU ports. Indeed, this trend has been reconfirmed in a very recent survey by Darbra et. al. [24] showing that the $93 \%$ of the surveyed ports had an environmental policy, $64 \%$ had a specific environmental budget and $64 \%$ were accredited by recognized organizations with environmental standards such as Port Environmental Review System (PERS) and ISO 14001. The PERS is formulated to be flexible and is considered as a step towards ISO 14001.

The European Union adopted conventions and regulations (e.g. 2001/96/EC) in order to enhance safety in maritime transport through the reduction of shipping accidents involving bulk carriers. The high number of bulk carrier accidents is mainly caused due to improper loading and unloading at bulk carriers terminals. The EU considers the above mentioned problem as a quality problem [26]. However, deficiencies in quality and safety initiatives may stem from managerial neglect of quality programs and processes. A failure to apply in the approved manner more comprehensive quality and safety management systems may involve internal organization problems and managerial oversights including top management misconceptions:

- management fails to empower employees;

- management fails to look beyond the port internal operations;

- management does not communicate quality and safety expectations;

- management neglects the role of training; and

- management overlooks the linkages between safety, security and quality.

Indeed, the last of the issues above is quite interesting and has been recently addressed in the literature [2] for integrating ISO 9001 with the International Safety Management Code for Safe Operation of Ships and Pollution Prevention (ISM code) of IMO (International Maritime Organization), creating a Integrated Quality and Safety Management System (IQSMS). 
Port security on the other hand, besides terrorism includes considerations regarding smuggling, stowaway, asylum seekers, illegal immigrants, sabotage, theft and pilferage of cargo. The ISO/PAS 20858 standard was prepared by the ISO Technical Committee ISO/TC 8 "Ships and marine technology", Subcommittee SC 11 "Intermodal and short sea shipping" is addressing security issues. It should be noted however that this particular standardization document, being a Publicly Available Specification (PAS), has not matured to a homophonous decision as an ISO standard but it has been accepted by at least the $2 / 3$ members of the committee casting a vote. The ISO/PAS 20858 is compatible to ISO 9000 and addresses the port facility security assessment issue, the development of port facility security plan (including countermeasures), and the skills and knowledge required of the personnel involved. The ISO/PAS 20858 is designed to assure that the requirements of ISPS code are met through appropriate security practices that can be verified by an outside auditor. Hence, the ISO/PAS 20858 establishes a framework assisting the development of a security plan as required by ISPS code and drafting a Port Facility Security Plan (PFSP).

The pathway to quality and safety is not unique due to a number of different issues, including ethnographic as well as other groups of factors such as political, economic, social, and technological. Furthermore, the adoption of a specific pathway for quality and safety management has different consequences. In this analysis distinct quality and safety standards have been introduced. In the first column of Table 2 different standards are being introduced, in columns 2 and 3 the mandatory or voluntary nature of the systems is provided, and in columns 4-7 the four categories (quality, safety/environment, safety/human and security) are provided. It is indeed rather clear that the various approaches and standards belong to more than one of the categories and in some instances they overlap. For example, PERS and ISO 14001 address environmental management issues, etc. A further important issue is the maintenance of the already accredited systems or perhaps their extension into more complicated standards. For example the implementation of PERS is thought to be a first step towards ISO 14001 etc. Quality and safety management approaches based on prevention [27] seem to be closer to the established practices and, therefore, easier to implement by ports, rather than other paradigms. On the other hand, such practices have been strained to the limits of their performance, and still the results need to be evaluated within the port industry. The quality and safety itself should not be perceived as unique, since each interested party such as management, employees, users, regulation authorities etc. prefer to evaluate and invest on quality and safety in a rather different way according to their point of view.

\section{Research conducted in Greek ports in relation to quality and safety standards implementation}

\subsection{Quality and safety standards penetration in the Greek} market

In Greece, the adoption of quality and safety standards has increased considerably [28]. Beyond that, in multidisciplinary studies (e.g. [29, 30]) it has been ascertained that basic problems during the development of quality and safety systems occur due to fixed wrong perceptions about quality approaches and due to the lack in trained personnel. Gotzamani and Tsiotras [31] state that the probable "failure" of an ISO 9001 system in the Greek market should be ascribed to the inability and/or the unwillingness of the management and the personnel to properly implement systems that assure quality. Despite the increasing interest in developing systems to assure quality and safety, though, and especially in Greece, empirical research on implementing these quality models on the various sectors of the economy is lacking. The conducted qualitative survey records the view of professionals on the development and implementation of quality and safety systems in the Greek ports.

In Greece, EU legislation (2001/96/EC) has been the main force for port quality and safety dispersion. Indeed, the EU legislation requires the implementation of ISO 9001 in bulk carrier terminals. So far a large number of bulk carrier terminals have certified their quality management systems with ISO 9001; the Piraeus and Thessalonica ports have been PERS accredited and Volos port authority makes/ has made every effort to develop a quality management system based on ISO 9001 for the entire port operations. These however are sparse initiatives if one considers the overall picture and quality assurance culture and practices are limited due to a number of reasons including the luck of a national quality and safety strategy for the port authorities, port authority understaffing and luck of funding etc. Facing the problems and/or improving quality and safety in the consolidated organizational daily routines in ports might in the end become a challenge. One may further argue that the various groups of interested parties in Greece, both within the port community and outside of it, do not immediately prioritize quality and safety initiatives in the same way.

\subsection{Questionnaire design and interviews}

The qualitative empirical study conducted was based on the development of a semi-structured questionnaire, which was addressed to experts from all the main Greek port authorities, i.e. 12 port authorities. The questionnaire design was in the lines of Gotzamani and Tsiotras [32], but with 
certain adaptations made during a preliminary pilot phase. The questionnaire comprises questions of closed type through a five-step Likert scale ranging from 1="total disagreement" to $5=$ "total agreement", so that those interviewed would express the degree of their agreement or disagreement. The final questionnaire is arranged in four sections as follows:

1. Port and Interviewee Profile: comprising a set of questions regarding information of the port and the interviewee.

2. Quality and Safety Accreditation: comprising a set of three questions (accredited, under development, plan to apply for accredition) for the most popular quality and safety international standards ISO 9001, ISO 14001, OHSAS 18001, EMAS, PERS.

3. Benefits \& Motives (i.e. expected benefits and reasons for applying a quality management system): comprising a set of 16 questions (shown in the first column of Table 1) for the perceptions of experts regarding the reasons or motivations for applying a quality and safety management system.

4. Shortcomings (i.e. expected drawbacks and problems the implementation faces): comprising a set of six questions (shown in the first column of Table 2) for the perceptions of experts regarding the possible shortcomings from the implementation of a quality and safety management system.

Each of the three last sections is accompanied by an open type question (a total of three open questions). The research did not aim at formulating generalizable results, despite the fact that according to Behrakis [33] the results and the descriptive analysis of the following paragraph produce indicative results based on the opinion of the experts in Greek ports.
The main port organizations in Greece are 12 and were converted into societe anonyms, governed by boards and controlled by the state. The Greek State is the sole shareholder in ten of these ports; while the other two ports (Piraeus and Thessaloniki) are listed in the Athens Exchange. In these two ports, the Greek State holds the $64.25 \%$ of the shares and the Companies' Articles of Association provide that the minimum holding of the Greek State in the Companies' share capital may not drop below the $51 \%$. The research took place during the second quarter of 2008 and the survey results have been reviewed in the first quarter of 2009. The authorities of the main 12 port organizations in Greece were conducted and asked to participate in the research subject to their experience in quality and safety management, i.e. having planed or implemented quality and/or safety international standards. At the end, (the) 10 out of the 12 port organizations agreed to participate in this research, i.e. $83 \%$ response rate, and experts for the interviews were indicated. The port authorities that agreed to participate covered a wide geographical scope and included the major Greek port authorities in the mainland and the islands, i.e. Piraeus, Thessaloniki, Elefsina, Patras, Igoumenitsa, Kavala, Volos, Irakleio, Rafina, Kerkyra. The majority of ports are "general cargo" and passenger followed by "dry bulks", "non-oil liquid bulks", "fresh produce and perishable" with around half of the ports handling "container" and "oil and petroleum".

\subsection{Results and discussion}

In this paragraph, the results from the three main aspects of this research, i.e. quality and safety accreditation, benefits $\&$ motives and shortcomings, are presented. The quality
Table 1 Summary of quality and safety approaches for the port industry

\begin{tabular}{|c|c|c|c|c|c|c|}
\hline \multirow[t]{3}{*}{ Quality/Safety Approaches } & \multicolumn{6}{|c|}{ Standard category } \\
\hline & \multicolumn{2}{|c|}{ Implementation } & \multirow[t]{2}{*}{ Quality } & \multicolumn{2}{|l|}{ Safety } & \multirow[t]{2}{*}{ Security } \\
\hline & Mandatory & Voluntary & & Environment & Human & \\
\hline ISPS code & $\sqrt{ }$ & & & & & $\sqrt{ }$ \\
\hline OECD guidelines & & $\sqrt{ }$ & & & $\sqrt{ }$ & \\
\hline OHSAS 18001 & & $\sqrt{ }$ & & & $\sqrt{ }$ & \\
\hline SA 8000 & & $\sqrt{ }$ & & & $\sqrt{ }$ & \\
\hline AA1000S & & $\sqrt{ }$ & & $\sqrt{ }$ & $\sqrt{ }$ & \\
\hline COM 2001/96/EC & $\sqrt{ }$ & & & $\sqrt{ }$ & $\sqrt{ }$ & \\
\hline ISO 9001 & & $\sqrt{ }$ & $\sqrt{ }$ & $\sqrt{ }$ & $\sqrt{ }$ & $\sqrt{ }$ \\
\hline ISO 14001 & & $\sqrt{ }$ & & $\sqrt{ }$ & & \\
\hline PERS & & $\sqrt{ }$ & & $\sqrt{ }$ & & \\
\hline ISO 28000 & & $\sqrt{ }$ & & & & $\sqrt{ }$ \\
\hline ISO/PAS 20858 & & $\sqrt{ }$ & & & & $\sqrt{ }$ \\
\hline
\end{tabular}


Table 2 Research results of the closed ended research questions expressing the benefits and motives for implementing quality and safety management standards

\begin{tabular}{llll}
\hline Section 3: Expected Benefits and Motives & Mean score & Stdev & $n$ \\
\hline Marketing tool & 4.60 & 0.70 & 10 \\
port image improvement & 4.50 & 0.53 & 10 \\
port services improvement & 4.40 & 0.52 & 10 \\
port operations improvement & 4.30 & 0.67 & 10 \\
required by the market & 4.30 & 0.67 & 10 \\
certification of competitors & 4.22 & 0.97 & 9 \\
competitive advantage & 4.20 & 0.63 & 10 \\
expansion tendency & 3.80 & 0.79 & 10 \\
Decision making & 3.80 & 0.63 & 10 \\
level of safety improvement & 3.78 & 1.09 & 9 \\
entrance to new markets & 3.70 & 0.82 & 10 \\
implementation of other quality and safety systems & 3.60 & 0.84 & 10 \\
satisfy legal requirement & 3.57 & 1.81 & 7 \\
required by current users /current demand & 3.50 & 0.76 & 8 \\
Reduction of cost & 2.70 & 1.06 & 10 \\
Future demand & 2.30 & 1.34 & 10 \\
\hline
\end{tabular}

and safety standards section of the interview was included to gain information regarding the penetration of the international standards in the Greek ports:

- At the time of the research, four mainland ports (Volos, Kavala, Elefsina, Thessaloniki) have implemented and certified ISO 9001 quality management systems; while Piraeus and Thessaloniki have both accredited the PERS environmental standard. In fact, the last two ports belong into the ECOPORTS network and were among the first that actually implemented the PERS standard.

- At the time of the research, the ports of Rafina, Patra, Igoumenitsa and Irakleio were planning to develop and implement ISO 9001 quality management systems, while quite recently Patra and Igoumenitsa have been certified by ISO 9001. The ports of Volos and Piraeus are planning to develop environmental management systems according to ISO 14001 international standard, while Elefsina is developing EMAS system for environmental management.

- The representative from Piraeus stated that they plan to implement ISO 14001 and EMAS; while an expert from Thessaloniki port stated that they plan to implement ISO 14001.

- Of the port experts interviewed, no one stated that OHSAS 18001 is to be implemented for personnel health and hygiene. This however was attributed by the experts to the relevant Greek and EU legislations and laws which are in fact obligatory hence no further actions are required. This is in fact not the only case were EU legislation and/or standards seem to overlap and hence some standards are preferred over others or not implemented at all.
- At the time of the research, the port of Kerkyra did not implement any of the quality and safety standards; while the representative stated that such and investment is not in the immediate plans of the port authority.

- From the ports included in the research, the majority has or is planning to apply for accreditation to more than one international quality and safety systems. Indeed, the port of Piraeus is planning to implement all together environmental systems (PERS, ISO 14001 \& EMAS) together with ISO 9001. Environmental concerns seem to be the prevalent and hence the Greek port organizations included in this research, are accrediting environmental management systems through international standards.

Although emphasis is evidently placed on environmental standards, the ISO 9001 seems to be quite popular in Greek ports for certifying the bulk carrier terminal. This is partly explained due to the reference made in EU legislation for bulk carrier terminals and partly explained by the nature of the standard. The ISO 9001 being an omnibus and voluntary international standard is the most general in scope covering all the standard categories. Although the ISO 9001 is widely acceptable, the omnibus nature of its requirements introduces variability and a high level of specialization is required if all quality/safety issues need are addressed in detail. Moreover, more specialized international standards for safety and security in ports can further specialize and complement ISO 9001 standard implementation. Surely, from our research it is suggested that quality and safety in ports need to be individually addressed through employment of more than one standard and/or approach. 
In the 3rd section of the questionnaire information about the perceptions of experts regarding the benefits and motives is gathered. The answers are presented in a hierarchal descending order in the first column of Table 2. In the next three columns, the mean score, the standard deviation and the sample size are provided. The mean score for each of the research questions is indicative to the degree a particular issue influences the Greek port organizations for implementing a quality and management system, in the scale from 1 "lowest" to 5 "highest". As can be seen from the hierarchy of Table 2, expected benefits and/or motives with a mean score above four are the following:

- marketing tool;

- port image improvement;

- $\quad$ port services improvement;

- required by the market;

- certification of others; and

- competitive advantage.

The experts representing the ports give the highest scores in issues (expected benefits and motives) regarding the market and competition (e.g. marketing, image, market requirement, certification of others and competition). These quite high scores may be indicative of an excessive appreciation of the new challenges and pressures ports in Greece face due to competition. Furthermore, although quality and safety assurance systems mainly aim at the improvement of the organization processes and not the quality of the final product [31] the experts give also high scores at the expected improvements of the services provided. This may express a desire to invest on quality and safety culture not only for marketing reasons. The very low scores of the "required by current users /current demand", "cost reduction" \& "future demand" are also interesting because they are indicating that quality and safety management systems are not perceived as requirements by port customers and are disassociated by the port services production cost.

The last section of the questionnaire investigates the perceptions of the experts regarding potential shortcomings from the implementation of the quality and safety international standards. In Table 3 the mean scores and the standard deviations are presented in a hierarchical order for each of the shortcomings suggested to the experts. The mean score is indicative to the degree to which the port representatives perceive as likely each of the statements/ shortcomings included in the questioner. The port representatives ascribe higher scores to shortcomings related to the staff involvement "personnel involvement for system development" \& "personnel involvement for system maintenance" due to the understaffing of the port organizations. Quite low scores have been assigned to cost for quality and safety system accreditation and maintenance implying that the cost of quality (cost of conformity) is not a real drawback. It should be noted however that in general low scores have been overall assigned to the statements of this section.

In the open-ended questions, the representatives of the Greek ports bring forward the problems of financing, understaffing and the need for qualified personnel, the lack of quality and safety management experience. Moreover, the port experts, who participated in this research project, reacted positively to the development of quality and safety systems. Though their comments they recognized the need for further applicable results including methods for quality and safety system integration. Many of the issues for quality and safety management are common to other economic sectors and the results of this study are analogous to the ones presented for example in Zantanidis et al., [29], Tsekouras et al., [30], Gotzamani and Tsiotras [31] etc. Finally, although the results are interesting, they should not be straightforwardly generalized for either the Greek ports or harbours, or outside the Greek environment.

Nowadays, the Greek port governance model is under an extensive reformation which is definitely going to affect quality and safety system implementations. This reformation includes administrative incorporations of nearby ports into larger port authorities controlling more than one port. Moreover, the privatization of some Greek port terminals, e. g. the container terminal in the port of Piraeus with COSCO enterprise as a port operator and the discussion for the container terminal Port of Thessaloniki, is gradually introducing a need for renegotiation of quality, safety and security standards. Moreover, a discussion is taking place for the privatization of cruise and passenger terminals in
Table 3 Research results of the closed ended research questions expressing the motives for implementing a quality management system

\begin{tabular}{llll}
\hline Section: Shortcomings & Mean score & Stdev & N \\
\hline Personnel involvement for system development & 3,50 & 0.71 & 10 \\
Personnel involvement for system maintenance & 3,50 & 0.85 & 10 \\
Reduced flexibility & 2,67 & 1.22 & 9 \\
Cost of system development and certification & 2,50 & 0.76 & 8 \\
Problematic implementation with port operations & 2,33 & 1.22 & 9 \\
Cost of system maintenance & 2,00 & 0.76 & 8 \\
\hline
\end{tabular}


Greek ports, through a cooperation with cruise operators. Indeed, passenger terminals within large Greek ports and the Greek ports which are mainly directed to the passenger and cruise market, they have not yet developed specifically quality and/or safety systems. A proper environment for the application of quality management could be achieved through an integrated multi-systemic quality and safety management model on a port authority level.

\section{Conclusions}

The results produced make available empirical information about the implementation of quality and safety management systems in Greek ports. The benefits expected and the motives for quality and safety system accreditation mostly associate to the various market pressures and seem to develop through the intensification of the competition; while the shortcomings examined are not perceived to be very likely by the experts, from a practical viewpoint, the findings provide practitioners and decision-makers with an indication that safety concerns for environmental management are indeed at the centre of attention; while there seems to be a tendency in favour of ISO 9001 implementation and certification.

There are, however, a number of questions that although have been addressed in other sectors they should be addressed specifically for the Greek ports and may boost quality, safety and security in the near future:

- What is the best possible framework for quality and safety system integration in Greek ports?

- What is the leadership necessary to steer a quality program?

- How staff can be empowered?

- From where should the resources come to establish and maintain a quality and safety program?

- What must be done to communicate across stakeholders in order to align perceptions and achieve clear quality and safety goals?

The above mentioned specific issues for the Greek ports adding to the complexity and are influenced by national and European changes and new policies. The question is not whether quality and safety is of interest, but which integrated quality and safety may provide the best approach for the Greek ports at the present time and in the future. Quality and safety has been the aspiration for research over the last decades and indeed many opinions on the different approaches toward the assurance and the improvement of quality for various business sectors have been suggested.

Acknowledgments We would like to express our gratitude to all who participated in the final formulation of the questionnaire and to all who participated in the research.
Open Access This article is distributed under the terms of the Creative Commons Attribution License which permits any use, distribution and reproduction in any medium, provided the original author(s) and source are credited.

\section{References}

1. Thai VV (2009) Service quality in maritime transport: conceptual model and empirical evidence. Asia Pac J Mark Logistics 20 (4):493-518

2. Celik M (2009) Designing of integrated quality and safety management system (IQSMS) for shipping operations. Saf Sci 47(5):569-577

3. ESPO (2005) http://www.espo.be/news/2005/News_plus/Plus\% 2011\%2006.pdf

4. Chlomoudis C, Kostagiolas P, Lampridis C (2005) Prospective employment of quality awards in the seaport industry: old solution to contemporary questions. Proceedings of the IAME International Conference, Limassol, Cyprus

5. Oakland JS (1989) Total quality management. Heinemann, Oxford

6. International Standards Organization (2005) ISO 9000: 2005 Quality management systems-Fundamentals and vocabulary. ISO, Geneva

7. Lopez RC, Poole N (1998) Quality assurance in the maritime port logistics chain: the case of Valencia, Spain. Supply Chain Manage 3:33-44

8. Marlow PB, Paixo AC (2003) Measuring lean ports performance. Int J Transp Manage 1:189-202

9. Myung-Shin H (2003) A comparison of service quality at major container ports: implications for Korean ports. J Transp Geogr 11:131-137

10. UNCTAD (1998) Quality management: the port of Nantes/ Saint Nazaire experience. UNCTAD, New York

11. Notteboom TE, Winkelmans W (2001) Reassessing public sector involvement in European Seaports. Int J Marit Econ 3:242-259

12. Piyush T, Hidekazu I, Masayuki D (2003) Shipper's port and carrier selection behaviour in China: a discrete choice analysis. Marit Econ Logist 5:23-39

13. Nir AS, Lin K, Liang GS (2003) Port choice behaviour-from the perspective of the shipper. Marit Policy Manage 30:165-173

14. Tyrinopoylos Y, Aifantopoulou G (2008) A complete methodology for the quality control of passenger services in the public business transport. Eur Transp 38:1-16

15. Pantouvakis A (2006) Port-Service quality dimensions and passenger profiles: an exploratory examination and analysis. Marit Econ Logist 8:402-418

16. Ugboma U, Oguede I, Ugboma O, Nnadi K (2007) Service quality and satisfaction measurements in Nigerian ports: an exploration. Marit Policy Manage 34:331-346

17. Pantouvakis C, Chlomoudis A, Dimas (2008) Testing the SERVQUAL scale in the passenger port industry: a confirmatory study. Marit Policy Management 35(5):449-467

18. Bichou K, Gray R (2004) A logistics and supply chain management approach to port performance measurement. Marit Policy Manage 31:47-67

19. Ro-Kyung, Prabir DE (2004) An alternative approach to efficiency measurements of seaports. Marit Econ Logist 6:53-69

20. Brooks MR (2007) Issues in measuring port devolution program performance: a managerial perspective. Res Transp Econ 17:599-629

21. Cherdvong S, Nowarat C, Wenresti GG, Chanachai L (2008) Environmental performance evaluation of an industrial port and estate: ISO14001, port state control-derived indicators. J Clean Prod 17:154-161 
22. Wooldridge CF, Tselentis BS, Whitehead D (1998) Environmental management of port operations - the port sector's response to the European dimension. In: Sciutto G, Brebbia CA (eds) Maritime engineering in ports. WIT Press, pp 227-242

23. ESPO (2005) Review of European performance in port environmental management, http://www.espo.be/downloads/archive/36f31a9e-e90240c1-85ef-a9826324f6d5.pdf. Accessed September 2009

24. Darbra RM, Pittam N, Royston KA, Darbra JP, Journee H (2009) Survey on environmental monitoring requirements of European ports. J Environ Manage 90(3):1396-1403

25. AAPA (1998) http://www.aapa-ports.org/Issues/content.cfm?Item Number $=989$

26. Chlomoudis CI, Pallis AA (2002) European port policy: towards a long term strategy. Edward Elgar, Cheltenham

27. Pando J, Araujo A, Maqueda FA (2005) Marketing management at the world's major ports. Marit Policy Manage 31:93-107
28. Lagodimos AG, Dervitsiotis KN, Kirkagaslis SE (2005) The penetration of ISO 9000 certification in Greek industries. Total Qual Manage 16:505-527

29. Zantanidis S, Tsiotras G (1998) Quality management: a new challenge for the Greek construction industry. Total Qual Manage 9:619-632

30. Tsekouras K, Dimara E, Skuras D (2002) Adoption of a quality assurance scheme and its effects on firm performance: a study of Greek firms implementing ISO 9000. Total Qual Manage 13:827-841

31. Gotzamani KD, Tsiotras GD (2002) The true motives behind ISO 9000 certification. Int J Qual Reliab Manage 19:151-169

32. Gotzamani KD, Tsiotras GD (2001) An empirical study of the ISO 9000 standards' contribution towards total quality management. Int J Oper Prod Manage 21:1326-1342

33. Behrakis TH (1999) Multi-dimensional data analysis. Methods and implementations, Livani, Athens 